\title{
Recollections of the Formative Years of IASSIST
}

\begin{abstract}
Before beginning, it is necessary to state that these are my recollections and in no way are meant to reflect recollections of other individuals involved with the formation of IASSIST. It is clear to me that we all have different interpretations of the past and come from different perspectives. I also apologize for the use of the first person at times, but that is necessary to assure that no one else receives blame for my interpretations and/or recollections. The flow of this presentation is not smooth, in part because so much was going on concurrently and the amount of effort that went into the establishment of IASSIST was too great to present coherently. It overwhelmed me then and it still overwhelms me. Reliving the past is a very emotional experience for me, as is this 25 th anniversary. It was certainly most unclear to me at the time that we would be able to establish IASSIST.

As many of us know, Toronto, Canada is the origin of IASSIST. During August, 1974, the VIIIth World Congress of the International Sociological Association met in Toronto. At this Congress, the International Social Science Council (ISSC) Standing Committee on Social Science Data (SCSSD) sponsored a conference on the Problems of Data Archives and Program Library Services. The conference was made possible through the very strong support of Stein Rokkan, President of the ISSC, and Elina Almasy, Secretary of the SCSSD, and the endorsement of conveners Erwin Scheuch, Chairman of SCSSD, Michael Aiken, University of Wisconsin-Madison, and Hagen Stegemann, the Zentralarchiv in Cologne, Germany.
\end{abstract}

Participants of the conference reviewed common problems that confronted individuals affiliated with or utilizing data repositories. In general, these problems were related to the production, acquisition, preservation, processing, distribution and use of electronic data files of interest to the social science community. The problems were also relevant to the development and maintenance of data archives and data libraries. by Carolyn L. Geda*

During this conference, many participants concluded that a communications network that provided a formal means for continued dissemination and sharing of information was needed. There were opportunities to meet each other through the Interuniversity Consortium for Political and Social Research (ICPSR), known at that time as the Inter-university Consortium for Political Research (ICPR), annual meetings and later biennial meetings. But a broader format was needed that would permit individuals to discuss the problems they were experiencing, permit collective efforts toward resolving these problems and establish workshops that would provide basic training in data management as well as training with new technologies. Toward this end, Alice Robbin, University of Wisconsin-Madison; Judith Rowe, Princeton University; and I, ICPR at University of Michigan; proposed to ICPR that a data management workshop be included in the Summer Program. When this workshop was offered, members of our peer group attended, thus demonstrating that there was indeed a need for an organization like IASSIST. Obviously, there were additional needs for advanced workshops and seminars. A little later, the European Archives addressed this need by offering expert workshops. In addition, ICPR Official Representatives were predominately academics, while individuals staffing the archives and the user services were increasingly becoming data librarians. In order to facilitate dissemination and sharing of information, I suggested to ICPR that a technical person as well as an academic be formally recognized for each ICPR member institution.

Returning to the results of the Toronto meeting, an Ad Hoc Organizing Committee (later to become the Steering Committee) for IASSIST was designated to draft a proposal for the establishment of an appropriate organization. Since the organization was to be international, additional individuals were added to the Committee to achieve regional representation from other parts of the world where interest in such an organization was felt to exist. Ultimately, in order to satisfy the mandate of ISSC and assure proper representation for an international organization, the Committee grew to 18 members. This was a large number of people with which to work, especially when all correspondence was to be sent to 
everyone on the Committee via air mail. We did not have e-mail, certainly as we know it today, to assist us. Many organizations were still using carbon copies as a means of distribution for documents and correspondence. Although we made every effort to achieve an international organization, the expectations set forth by ISSC were completely unrealistic. Organizations existed on paper for several of the regional areas, but we were not able to develop active regional secretariats in each of the areas designated. Our attempts to comply even included reproducing additional copies of the newsletter to send to these secretariats for distribution to their interested individuals. The cost of these additional activities was borne by our home institutions as part of the commitment to IASSIST. Eventually, we were forced to say that we could not expect an organization of individuals to continue to support such costs and the regional secretariats were scaled back to the areas that actually had members.

As you might also expect, we were a very vocal group of people, each of whom obviously thought they were right about everything. Nonetheless, I found myself chairing this Organizing Committee. It is unclear why I accepted this charge; all I recall is that I thought ICPR had a mailing list that would form the base of individuals that might be interested in joining such an organization. In assuming this role, I tried very hard to prevent the feeling of American dominance, American Imperialism and particularly American Data Imperialism. Additionally, I continually struggled with a concern that ICPR might be perceived as dictating to the Committee or that IASSIST might become the puppet of ICPR.

The first task of the Committee was to construct and agree upon an acronym. This acronym evolved at the infamous bar in Toronto. Once the acronym of IASSIST was agreed upon, we had the problem of finding appropriate words for it. Although we were very pleased with the acronym, we frequently had and continue to have problems remembering the actual name of the organization!

It should be noted that not all individuals felt IASSIST was a good idea. A well respected colleague and friend of mine thought it was a bad idea and vehemently spoke against it. Several days later I received the following letter:

\section{Carolyn,}

About the conversation in the bar-I'm really sorry that I spoke as I did. It was an unthinking reaction which did not become clear to me until later when I realized that, as opposed to most people I know these days, you really cared about the ideas and plans for IASSIST. Real interest and concern is such a fugitive quality these days - one which I terribly admire - and thus am even more sorry to have listened and responded so negatively and so unfeelingly. In a way, though, I'm almost glad it happened since it made me realize that things still can get accomplished, if only because some people are ready to really work to achieve such accomplishments.

In retrospect I should have considered this a serious warning. My friend, Lorraine Borman from Northwestern University, recognized far better than I what was going to be involved. And, in fact, when I returned to ICPR to discuss the creation of IASSIST, I discovered that some ICPR staff thought we were forming a union!

While in Toronto in 1974, the Committee met several times in an attempt to begin laying the foundation for IASSIST. Some of the questions or problems raised during these discussions were:

Scope and type of membership

Objectives

Activities

Affiliation with other organizations

Newsletter

Governance

Participation of developing countries

Membership fees

One of the most difficult issues was whether to establish an independent association with its own newsletter or to affiliate with an existing association whose objectives were consistent with those of IASSIST. Included in this issue was the relationship IASSIST might have to the ISSC Standing Committee on Social Science Data. The affiliation with another association was considered in anticipation of a relatively small membership. Less time would have been required to activate IASSIST if the Committee had decided to affiliate with an existing association. Eligible associations were identified and considered, but the resultant lack of autonomy and independence for IASSIST was seen as too great a disadvantage. The Committee felt the same way about a newsletter.

As mentioned earlier, Alice Robbin, Judith Rowe and Carolyn Geda were among the United States prime movers in the founding of IASSIST. Ultimately, we were branded as "American Female Functionaries" in part because we did not have PhDs. We were non-PhD females breaking from the established ISSC composed of men who were professors at universities and directors of the archives.

In April 1975, at the European Consortium for Political Research meetings, the Committee met again with a draft constitution and proposed a set of Action Groups. The constitution was not approved, but significant progress 
was made on the mandates of the Action Groups. Each Action Group was to address a problem area or set of related problems not being systematically addressed by another organization, and would look toward a final, hopefully publishable, product. Any proposed Action Group that could not meet those criteria was deleted. Two Action Groups were deleted: One dealing entirely with matters of archival policies and the other dealing with computer software. On the other hand, since data archive development was defined differently in Europe and North America, a decision was made to create an additional Action Group to deal with data organization and management. Emphasis was also placed on the desirability of developing Action Group products that were consistent with the ongoing professional activities of the membership. In this way the efforts devoted to IASSIST tasks by members would provide direct benefit to their home institutions.

At that point in time each Action Group was perceived as having members from all regions in IASSIST. The Action Group structure was replaced by a regional structure because it soon became obvious that problems of international travel and communication precluded effective activity at this level. In addition, as the Regional Secretariats began to establish Action Groups, it was apparent that a regional or national focus and redefinition was required to meet the different needs, interests and levels of development. Parallel Action Groups were recommended, in some instances with slightly different mandates. The chairpersons of the Action Groups were to be responsible for communicating with the chairpersons of the same or similar Action Group in other regions. Action Groups would be activated or dissolved according to the recommendations of the membership and/or Action Group chairpersons. Action Groups in existence were:

Data Archive Registry

Data Acquisition

Data Documentation

Classification

Data Archive Development

Process-Produced Data

Data Organization and Management

Regional Secretariats were established to be responsible for the recruitment of members, receipt of membership fees, development of Action Groups, scheduling of regional meetings and handling of other associational activities. The regional focus of the association allowed members' interests to be served more directly and helped to spread the burden of membership recruitment. Membership meetings of regions could be more readily scheduled and better attended than could international meetings. Regional
Secretariats were designated for the following areas: South and Central America, Canada, Asia-West Africa, West Europe, East Europe and the United States. Australia was interested in joining pending sufficient membership. Mass mailings were sent by the Secretariats to approximately 1000 people- 123 in Asia/Africa, 71 in Canada, 282 in Europe, 96 in Central and South America and 493 in the United States.

At approximately the same time the European archives felt a need for greater recognition of their roles as national archives, particularly within ICPSR. Prior to this point, individual archives and universities within Europe were members of ICPSR. The formation of National membership in ICPSR centrally organized around the national data archives permitted a stronger role by each of the archives. Yet the Europeans also felt a need for an organization of organizations within which they could continue to operate and develop policies. An organization of individuals was not the format in which they operated. It was imperative that IASSIST be an international organization, not just a North American organization, that would permit the Europeans to affiliate with IASSIST.

The issue of an organization of individuals versus an organization of organizations had to be resolved. The Committee met again in Edinburgh, Scotland, in August 1976, where the International Political Science Association (IPSA) was meeting. Another constitution for IASSIST had been drafted and was presented. During this meeting, I endured a lengthy lecture on how to craft a constitution. We seemingly made no progress on reaching an agreement on anything. Discouraged and drained, I left the meeting around midnight. (This had always been a very hard working group that frequently met into the night.) I arrived back at the dormitory where I was staying and called my director, Jerome Clubb. I said I had done my best to reach agreement but had failed. IASSIST was not going to be accepted. Jerry gave me permission to return to the United States the next day in spite of the fact that he and I had additional meetings to attend after the IPSA meetings. He recognized that I had disintegrated and simply had no more stamina. His support was most encouraging. The next day the Committee met again. Somehow it had been concluded, in large part due to the extraordinary abilities of Stein Rokkan to work through very difficult international situations, that there could be an IASSIST and an organization of organizations, which became the International Federation of Data Organizations (IFDO). The constitution was approved with the understanding that IASSIST was a fledgling organization and as the organization developed, the constitution would have to be amended. It was also acknowledged that the Committee of 18 people might be too large to function effectively.

We were all growing up professionally at this time and the growing pains placed strains in all directions. Nevertheless, 
it was a golden era and a very special time to learn a great deal from each other and form lasting professional and personal relationships.

Throughout the formative years of IASSIST, which seemed to go on forever, many people worked untold hours. There are simply too many people to name individually, but I remain eternally grateful for their commitment and very hard efforts. One person in particular stands out, my good friend and colleague Per Neilsen who kept European IASSIST together and acted as their Secretariat. Others who acted as pillars of strength and are no longer with us are Stein Rokkan, Warren Miller, Murray Aborn, Harold Naugler and Ed Hanis, who was our first treasurer.

In conclusion, I hope I have managed in some small way to convey the rich legacy of IASSIST. Although it remains a small organization, it is one filled with deeply committed individuals who are always eager to assist others struggling in our field in any way possible. We continue to work towards the resolution of what sometimes seems to be the same set of problems we had 25 years ago, just packaged differently. IASSIST gives us an ongoing international format for listening to each other, of which we must continue to take advantage, and a format in which we can identify the similarities and differences of our approaches and work collectively on resolutions.

* Carolyn L. Geda was the first president of IASSIST 19761979 and has served on many IASSIST committees since then.Contact information: cg3@ix.netcom.com 